\title{
Designing for Context versus the Lock-In Effect of Free Global Digital Platforms: A Case of SMEs from Nigeria
}

\author{
Adedamola Tolani ${ }^{1 \text { [0000-0003-1429-0902] }}$, Adebowale Owoseni ${ }^{3[0000-0001-8360-3197]}$ and Hos- \\ sana Twinomurinzi ${ }^{2[0000-0002-9811-3358]}$ \\ ${ }^{1,3}$ School of Computing, UNISA, South Africa \\ ${ }^{2}$ School of Computer Science and Informatics, De Montfort University \\ damolat@gmail.com, adebowale.owoseni@dmu.ac.uk, \\ twinoheunisa.ac.za
}

\begin{abstract}
This paper reports on the design and evaluation of an app that was designed using the newly created elaborated action design research method and critical realism to overcome the social and economic structural challenges that SMEs in Nigeria face. The results show that even though the app took into account the full range of SME dynamic capabilities and proved valuable, SMEs remained dependent on the affordances of the existing global digital platforms. The findings point to the lock-in effect of freely available digital platforms and that SMEs tend to default to their path dependency (and therefore the existing global digital platforms) rather than explore local digital innovations. The paper suggests that intentional efforts from powerful actors such as government might be necessary to overcome the path dependency and lock-in effect of freely available global digital platforms. The paper identifies the extra efforts required to sustain local digital innovation in the face of well-resourced global digital platforms. The paper further reveals the utility of the new elaborated action design research method for designing for context. Six (6) design principles for designing for SMEs in resource-constrained contexts were also elicited.
\end{abstract}

Keywords: Small and Medium-Sized Enterprises (SMEs), Digital Platforms, Mobile App, Dynamic Capabilities (DC), Particularism, Context

\section{$1 \quad$ Introduction}

Digital technologies play an integral role in enhancing the dynamic capabilities (DCs) of Small and medium sized enterprises (SMEs) to make effective decisions and take planned and strategic decisions. DCs represent ways in which organisations reorganise their internal resources and competences in response to evolving business environments [1]. For example, digital technologies influence product quality and services, resulting in the improvement of SME DCs [2]. SMEs also use mobile apps, particularly social media and e-commerce platforms [4-6], to serve their customers, maximize new business opportunities and achieve market advantage [5].

SMEs in Nigeria face structural challenges including lack of skilled human resources, limited training opportunities, poor policy implementation, inadequate 
infrastructure, lack of funding support and access to credit facilities, multiple tariffs and regulatory challenges (i.e. tax regulatory problems, delays in organisation and product registrations) compared to their counterparts in high-income countries [6-9].

This paper therefore sought to develop a context-suitable mobile app artefact that integrates the DCs of SMEs in Nigeria [7-9]. The paper posited the necessity of understanding the structural issues that influence SMEs in developing country contexts $(\mathrm{Ni}$ geria) from the critical realist philosophy. Critical Realism (CR) is a meta-theoretical philosophy by Bhaskar [11] that illustrates the significance of distinguishing knowledge from existence. CR allowed this study to identify the social and economic structural patterns that influence SMEs, and subsequently design a contextual mobile app for Nigeria SMEs [10-11]. Specifically, the study sought to: design a mobile app artefact that allows SMEs in Nigeria to identify opportunity from a critical realist viewpoint.

The remainder of the paper is structured as follows: The next section presents the related work. It is followed by the research approach and a section on the design of the digital artefact. The final section presents the conclusion and inferences.

\section{Related work}

\subsection{SMEs and dynamic capabilities (DCs)}

SMEs in Nigeria are classified as businesses with a total cost of less than five hundred million $(500,000,000)$ Naira $(\$ 1,383,040)$, excluding land, and fewer than two hundred (200) employees. Ninety six per cent of businesses in Nigeria are categorised as SMEs according to the Central Bank of Nigeria [14]. SMEs are valuable to Nigeria's economic growth. They provide entrepreneurial and leadership development of talents, the lack of which is often an impediment to economic development. The continuous development of these highly skilled entrepreneurial resources and competences drawing on DCs and digital technologies is important to the sensing and seizing of new business opportunities.

DCs are organisational and strategic routines that enable organisations to reorganise their internal resources and competencies continuously to create new sources of competitive advantage [1]. DCs involve the renewal of business processes, allocations of human resources, knowledge development and transfer, and decision-making in direct response to new business needs [15]. DCs are fundamental to SMEs as they reflect the ability to create, modify and renew business processes [16].

\subsection{Mobile apps and SMEs}

Mobile apps are software programs that run on mobile devices and integrate specific digital platforms to accomplish specific tasks for individuals and organisations [17]. Mobile apps enable SMEs to take effective decisions and planned and strategic risks while carrying out their business processes seamlessly [18].

Owing to dynamic market needs, SMEs continually seek new approaches to differentiate their businesses using mobile apps [19]. The use of mobile apps is integral to SMEs as these apps assist SME owners in enhancing their ability to make effective 
decisions while developing, analysing, processing and transforming information. The adoption of mobile apps can also enable SMEs to increase their revenue growth and create more jobs faster than their competitors [20].

This paper reports on the design of a contextual mobile app from an ensembled viewpoint that sees ICTs as part of dynamic social networks that include people, their DCs and relationships, and artefacts [21].

\subsection{Designing for context}

Context can be defined as the situation within which a phenomenon of study occurs in an organisation [22]. It also refers to the circumstances that produce the setting for an event that is well understood to capture clear constructs and specific implications [1617]. Context enables an in-depth understanding of the structural challenges and events that affect a phenomenon of interest. Takavarasha et al [25] articulated the relevance of context to determine where and when ICTs are designed and used to conform with diverse cultures, capabilities, and social settings.

In the Nigerian context, SMEs are looking at new approaches to uniquely differentiate the products and services they offer because of dynamic market needs [5]. An approach largely considered by SMEs is the use of ICTs, such as mobile apps. ICTs are key enablers of SMEs in the development of products, market research and access to information [19-20]. ICTs enhance the growth and development of SMEs in dynamic socio-economic environments, thereby enabling them to compete favourably in a fastpaced environment [21-22]. The research reported here focused on creating and evaluating a digital artefact (mobile app) designed around contextual constructs developed from the DCs of SMEs in Nigeria using the elaborated action design research (EADR) [9].

\subsection{Elaborated Action Design Research}

EADR is a problem-driven approach that closely links activities that are specific to the design of an artefact while simultaneously evaluating it [29]. The EADR cycle follows the stages: diagnosis, design, implementation and evolution (Fig. 1).

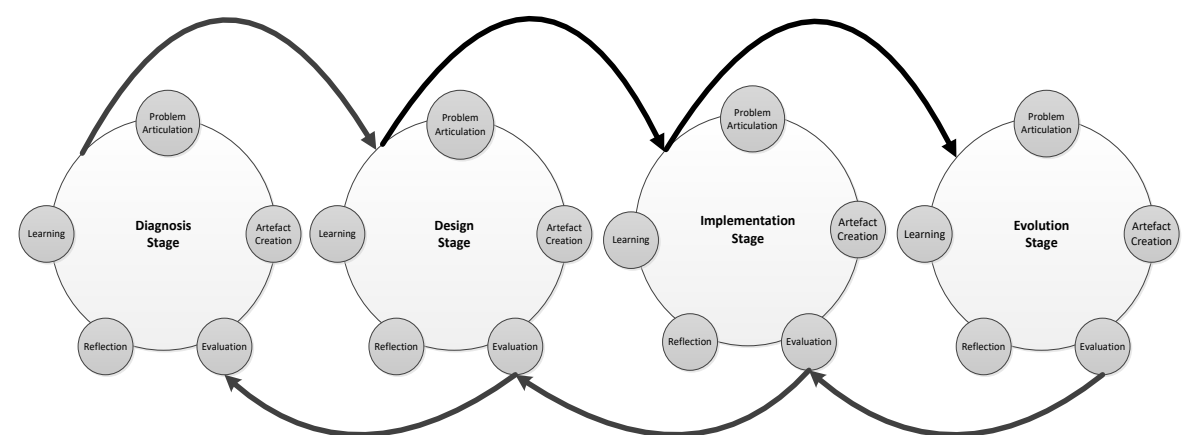

Fig. 1. Stages of EADR (Adapted from Mullarkey \& Hevner [29]) 
Each stage of EADR includes the following activities: problem articulation, creation of artefact, artefact evaluation, new knowledge creation through reflection and learning formalisation [30]. These activities are carried out iteratively, as a sequence of specific tasks, based on certain principles to create new knowledge through learning formalisation. The EADR approach was further guided by the CR philosophy in the diagnosis phase to identify the underlying contextual mechanisms that exist in SMEs. This ensured that the design of the mobile app was based on rigorous theoretical and empirical evidence, and at the same time the relevance of the contextual mechanisms [42-43]. This study will use the EADR method to discuss the development and evaluation of the proposed ICT artefact.

\section{$3 \quad$ Research approach}

The EADR method was adopted in the study to design and evaluate the artefact following the procedures depicted in figure 2 .

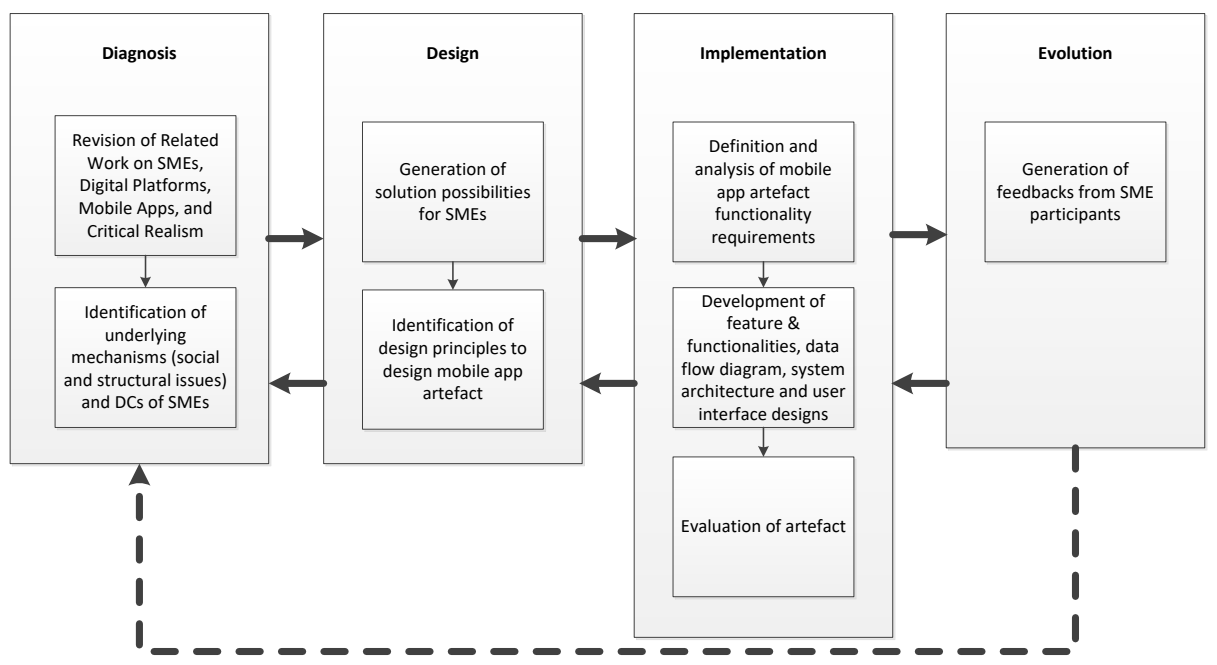

Fig. 2. Research Process Flow Diagram

In this study, the researcher took the following steps as illustrated in the research process flow diagram:

1. Identifying underlying mechanisms to reveal social and structural issues experienced by SMEs in Nigeria.

2. Generating solution possibilities and design principles to address the issues experienced by SMEs.

3. Designing the artefact (including functionality requirements, a data flow diagram, the system architecture and user interfaces).

4. Evaluating the artefact to assess its efficacy in SMEs. 


\subsection{Identification of underlying mechanisms in Nigerian SMEs}

\section{Critical realism domains of SMEs in Nigeria}

CR served as the philosophical lens to uncover the underlying mechanisms that influence SMEs, and served as the basis for the design and development of the mobile app artefact for SMEs in Nigeria. CR maintains a strong focus on ontology to illustrate that reality exists and that it is possible to create new knowledge about it [33]. According to Bhaskar [11], objective reality is identified and described in three hierarchical strata of reality: the real, the actual and the empirical.

The real includes social structures and mechanisms that exist independently of our perception of them; some of these are observable and others are not. Causal generative mechanisms emerge from the social structures in the real domain of CR [34]. These causal mechanisms describe the structural issues in Nigeria context [35], which this research sought to reveal. The actual domain consists of observable events that occur as a result of the interactions of causal mechanisms (i.e. the real) [35]. The empirical domain comprises events that occur through observations of experiences [33]; in this study these are the noticeable observations of the subjects being examined.

Previous research by Tolani et al. [36] identified the underlying mechanisms in the CR domain of SMEs, namely productivity, access to local market information, training and access to SME programmes that generate events (SME business processes and DCs). (See supplementary material). The identified mechanisms allowed this study to uncover the structural elements (i.e. problems) in SMEs. These structural elements or problems are discussed below.

SMEs use different freely available ICTs (i.e. digital platforms) with unique features that lack interoperability as a result of the loosely structured nature of their business. Also, the existing ICTs used by SMEs are globally oriented and lack the provision of local information services, which result in logistics, finance, human resources, taxation and regulatory issues. This problem affects SMEs' ability to access local market information and trends in Nigeria. In addition, SMEs lack continuous skills development owing to the inability of government agencies to convey information to SMEs or to deliver training via digital platforms. Finally, funds and capacity-building programmes set up by government agencies are inaccessible to SMEs as a result of inadequate dissemination of information and an ineffective organisational system.

The contextual mechanisms discussed above are the structural issues that exist in SMEs and provide an entry point to articulating the possible solutions and design principles to create the artefact.

\section{Design principles for context}

The paper adopted the contextual mechanisms as the requirements for the artefact to be developed [30]. The following are the five design principles that were identified: Digital artefacts for SMEs in resource constrained low-income countries should:

1. Incorporate the dynamic capability to identify local business opportunities.

2. Demonstrate the ability to do business in unstructured environment.

3. Gain easy access to SME government programmes and funding.

4. Provide access to entrepreneurship learning content.

5. Consider the local dialect and language. 


\subsection{Design of the contextual artefact}

The mobile app artefact included the design principles based on the ensemble viewpoint to group SME owners, their relationships, existing ICTs, DCs and SME business processes in an organized way [37].

The design of the app, "MyBizAssistant" included features and functionalities, a data flow diagram, system architecture and user interface designs of the artefact (see supplementary material). The functionalities of the app and the DCs of SMEs in Nigeria are illustrated in Table 1.

Table 1. Functionalities of MyBizAssistant artefact and related DCs

\begin{tabular}{|c|c|c|}
\hline Functionality & DCs of SMEs & Description \\
\hline \multirow[t]{8}{*}{ Productivity } & Sales and marketing & \multirow{8}{*}{$\begin{array}{l}\text { The mobile app enables SMEs to } \\
\text { carry out sales, marketing and brand- } \\
\text { ing activities, to manage expenditure, } \\
\text { to interact and participate (i.e. com- } \\
\text { municate), and to do market research } \\
\text { using existing digital platforms. }\end{array}$} \\
\hline & Market research & \\
\hline & Interaction and participation & \\
\hline & Product marketing and research & \\
\hline & Review operations & \\
\hline & Create new product ideas & \\
\hline & Product branding & \\
\hline & Expenditure management & \\
\hline \multirow{3}{*}{$\begin{array}{l}\text { Access to local } \\
\text { market infor- } \\
\text { mation }\end{array}$} & Marketing strategy & \multirow{3}{*}{$\begin{array}{l}\text { The mobile app enables SMEs to } \\
\text { overcome the organisational con- } \\
\text { straints and to get easy access to in- } \\
\text { formation tailored to the local market. }\end{array}$} \\
\hline & $\begin{array}{l}\text { Access government SME pro- } \\
\text { grammes in Nigerian languages }\end{array}$ & \\
\hline & Market research & \\
\hline Training & $\begin{array}{l}\text { Training and capacity develop- } \\
\text { ment }\end{array}$ & $\begin{array}{l}\text { This mobile app enables SMEs to ac- } \\
\text { cess training easily for continuous } \\
\text { skills development. }\end{array}$ \\
\hline \multirow{2}{*}{$\begin{array}{l}\text { Access to SME } \\
\text { programmes }\end{array}$} & Marketing strategy & \multirow{2}{*}{$\begin{array}{l}\text { The mobile app enables the digital } \\
\text { dissemination of information on SME } \\
\text { programmes and funding. }\end{array}$} \\
\hline & $\begin{array}{l}\text { Access government SME pro- } \\
\text { grammes }\end{array}$ & \\
\hline
\end{tabular}

\subsection{Evaluation of the artefact}

The evaluation of the app was carried out with 20 SMEs using observational design evaluation methods through field studies [32]. The respondents provided five-point Likert-scale responses ranging from (1) "Not At All" to (5) "A Great Deal" to ten (10) questions as feedback on the app DC constructs (i.e. sales and marketing, strategic planning, expenditure management, trainings, communications, access to local market information, access to government programmes, market research and generate new product ideas) and app usage preference construct (i.e. preference to use MyBizAssistant over the freely available apps). The study conducted only one evaluation cycle due to time and logistical constraints.

Using descriptive statistics, the data fulfilled validity and normal distribution requirements: data points are within \pm 3 standard deviation from the mean, and had kurtosis and skewness within an acceptable range of \pm 2 and close variances [38]. Minitab 18 statistical software was used for the statistical tests. 


\section{$4 \quad$ Results}

\subsection{Evaluation: MyBizAssistant mobile app artefact}

The SMEs in this study included 20 businesses that cut across 8 industries in Nigeria: agriculture, manufacturing, food, event planning, medical, information technology, gifts packaging, clothing. SME owners rated the app as an "effective tool" as follows: communication with customers (4.20); generating new product ideas (4.15); access to local market information (3.95); market research (3.90); attending entrepreneurial and leadership training (3.90); sales and marketing (3.85); expenditure management (3.75); strategic planning (3.65); access to government programmes (3.60); and prefer MyBizAssistant over existing global digital platforms (3.30). (See supplementary material). The app uses smartphone features (e.g. phone contacts and push notifications) and integrates existing digital platforms and government APIs to allow SME owners to maximize business opportunities. It gives SMEs easy access to information on the local market and SME programmes. The app also allows SMEs to interact in a Nigerian language (Yoruba, Ibo or Hausa), and to facilitate participation in training and collaboration. A comparison between MyBizAssistant and other digital platforms is described in Table 2 .

Table 2. Functionalities and Related DCs of MyBizAssistant artefact compared with other digital platforms

\begin{tabular}{llcccc}
\hline Functionality & \multicolumn{1}{c}{$\begin{array}{c}\text { DCs of } \\
\text { SMEs }\end{array}$} & $\begin{array}{c}\text { MyBizAs- } \\
\text { sistant }\end{array}$ & Facebook & Instagram & WhatsApp \\
\hline Productivity & $\begin{array}{l}\text { Sales and } \\
\text { marketing }\end{array}$ & Yes & Yes & Yes & Yes \\
\cline { 2 - 6 } & $\begin{array}{l}\text { Market re- } \\
\text { search }\end{array}$ & Yes & Yes & Yes & No \\
\cline { 2 - 6 } $\begin{array}{l}\text { Interaction } \\
\text { and partici- } \\
\text { pation }\end{array}$ & Yes & Yes & Yes & Yes \\
\cline { 2 - 6 } $\begin{array}{l}\text { Product mar- } \\
\text { keting and } \\
\text { research }\end{array}$ & Yes & No & Yes & No \\
\cline { 2 - 6 } $\begin{array}{l}\text { Review op- } \\
\text { erations }\end{array}$ & Yes & No & No & No \\
\hline $\begin{array}{l}\text { Create new } \\
\text { product ideas }\end{array}$ & Yes & Yes & Yes & No \\
\hline
\end{tabular}




\begin{tabular}{|c|c|c|c|c|c|}
\hline & $\begin{array}{l}\text { Product } \\
\text { branding }\end{array}$ & Yes & Yes & Yes & Yes \\
\hline & $\begin{array}{l}\text { Expenditure } \\
\text { management }\end{array}$ & Yes & No & No & No \\
\hline \multirow{3}{*}{$\begin{array}{l}\text { Access to lo- } \\
\text { cal market in- } \\
\text { formation }\end{array}$} & $\begin{array}{l}\text { Marketing } \\
\text { strategy }\end{array}$ & Yes & Yes & Yes & No \\
\hline & $\begin{array}{l}\text { Access gov- } \\
\text { ernment } \\
\text { SME pro- } \\
\text { grammesin } \\
\text { Nigerian lan- } \\
\text { guages }\end{array}$ & Yes & No & No & No \\
\hline & $\begin{array}{l}\text { Market re- } \\
\text { search }\end{array}$ & Yes & Yes & Yes & No \\
\hline Training & $\begin{array}{l}\text { Training and } \\
\text { capacity de- } \\
\text { velopment }\end{array}$ & Yes & No & No & No \\
\hline \multirow{2}{*}{$\begin{array}{l}\text { Access to } \\
\text { SME pro- } \\
\text { grammes }\end{array}$} & $\begin{array}{l}\text { Marketing } \\
\text { strategy }\end{array}$ & Yes & No & No & No \\
\hline & $\begin{array}{l}\text { Access gov- } \\
\text { ernment } \\
\text { SME pro- } \\
\text { grammes }\end{array}$ & Yes & No & No & No \\
\hline
\end{tabular}

The results suggest that the app has the potential to enhance SMEs' sales, marketing and strategic planning activities. In addition, the app can help SMEs to gain improved access to government programmes. However, a few SME owners indicated the need for deeper integration into government and market research content platforms to create seamless interaction with SME owners and to improve business insight. The evaluation confirms the usefulness of the app as a suitable tool for SME owners to enhance their DCs to identify opportunities. It also reveals functional issues and changes that could be made (as indicated by the respondents).

The functionalities of MyBizAssistant compared to the top 3 digital platforms used by Nigerian SMEs (Facebook, Instagram, WhatsApp) illustrated in table 2 shows that the digital platforms only used by SMEs for sales and marketing, interaction and participation, product branding, and market research purposes; and are not suitable for access to localised information on market trends, government programs, funding, and training. Despite the availability of a better alternative "MyBizAssistant" that is based 
on the Nigerian context, SMEs still preferred the digital platforms because they are free, easily accessible, familiar and readily available to use; thus, creating a lock-in effect.

\subsection{Discussion: Lock-in effect of digital platforms on SMEs in Nigeria}

The findings in this study showed that SMEs only moderately preferred the MyBizAssistant over freely available global digital platforms. This is a symptom of what is labelled a "path dependency" syndrome, which is seen not only in SMEs, but also in larger organisations. Path dependency refers to established organisational routines that endure despite evidence that the routines no longer provide any value [45-46]. This result to the lock-in of SMEs as it pertains to the use of these digital platforms. This can be detrimental to the business as it often results in a reluctance to adapt to ICT evolution and/or reverse past decisions regarding ICT use.

The study therefore included one more design principle: Contextually designed apps for SMEs should engage with powerful actors especially government agencies in order to encourage adoption. MyBizAssistant app was integrated to government platforms to create a seamless interaction with SMEs and push contents that inform SMEs about product registration, tariffs, waivers, and funding opportunities.

\section{Conclusions}

The research focused on the design and evaluation of a contextual mobile app for SMEs in the resource constrained Nigerian context based on requirements that were elicited from critical realist mindset. The theoretical underpinnings of the business requirements were guided by the DC framework. The DC considers the dynamic nature of organisations and has at its centre innovativeness and resourcefulness of existing organisational resources. The research adopted the EADR to allow for the continuous diagnosis, design, implementation and evolution of the app.

Using CR the research the structural needs that affect SMEs' DCs were elicited, and these provided perspective which inform how SMEs use mobile apps in Nigeria. Subsequently, an app was created using EADR approach which enabled SMEs to improve their ability to maximize business opportunities. The app was evaluated to determine its relevance. The resultant design artefact was shown to be relevant for SMEs in allowing access to information and data about their business and operations, government SME programmes and cost-effective vendors. Particularly, the app could enhance sales, marketing, strategic planning, easy access to local market information and SME programmes. However, SMEs appears to be locked in to the freely available global platforms such as Facebook, Instagram and WhatsApp, revealing a strong path-dependency effect.

For SMEs to maximize the benefits of contextual-suitable apps, and improve DCs, the effects of path dependency, and the lock-in effect of these powerful, freely available global digital platforms [41], would require inputs from external and powerful actors such as government [42] to raise adoption among SMEs [43]. The awareness could 
begin with incremental steps in advocacy and incentivising usage of local digital platforms [44].

The paper was limited in the requirements space, the number of SMEs that evaluated the app and the time provided to test the app. Further research could be conducted on a longitudinal basis in a different context and country as adoption of digital technologies in society is often a gradual process.

\section{References}

1. Teece, D., Shuena, A., Pisano, G.: Dynamic Capabilities and Strategic Management. Strategic Management Journal. (1997).

2. Esselaar, S., Christoph, S., Ali, N., Deen-Swarray, M.: ICT Usage and Its Impact on Profitability of SMEs in 13 African Countries. In: 2006 International Conference on Information and Communication Technologies and Development. IEEE. pp. 40-47 (2006).

3. Constantinides, P., Henfridsson, O., Parker, G.: Platforms and Infrastructures in the Digital Age. (2018). https://doi.org/10.1287/isre.2018.0794.

4. Asadullah, A., Faik, I., Kankanhalli, A.: Digital Platforms: A Review and Future Directions. (2018).

5. O'Halloran, J.: SMEs Get Productivity from Mobile Applications, http://www.computerweekly.com/news/2240088236/SMEs-get-productivity-frommobile-applications, last accessed 2017/06/20.

6. Nwagwu, I., Oni, T.: Lagos and Its Potentials for Economic Growth, https://ng.boell.org/2015/07/02/lagos-and-its-potentials-economic-growth, last accessed 2018/09/30.

7. Muller, P., Robin, N., Jessie, W., Schroder, J., Braun, H., Becker, L., Farrenkopf, J., Ruiz, A., Caboz, S., Ivanova, M., Lange, A., Lonkeu, O., Mühlschlegel, T., Pedersen, B., Privitera, M., Bormans, J., Bogen, E., Cooney, T.: Annual Report on European SMEs 2018/2019. (2019).

8. Urquhart, C.: Response to Davison and Martinsons: Context is king! Yes and no - It's still all about theory (building). Journal of Information Technology. 31, 254-256 (2016). https://doi.org/10.1057/s41265-016-0002-x.

9. Davison, R., Martinsons, M.: Context is king! Considering particularism in research design and reporting. Journal of Information Technology. 31, 241-249 (2016). https://doi.org/10.1057/jit.2015.19.

10. Andoh-Baidoo, F.: Context-specific theorizing in ICT4D research. Information Technology for Development. 23, 195-211 (2017). https://doi.org/10.1080/02681102.2017.1356036.

11. Bhaskar, R.: A Realist Theory of Science SE - Radical Thinkers. Verso (1975).

12. Heeks, R., Wall, P.J.: Critical Realism and ICT4D Research. Springer International Publishing AG (2017). https://doi.org/10.1007/978-3-319-59111-7_14.

13. Ng, E., Tan, B.: Achieving state-of-the-art ICT connectivity in developing countries: The Azerbaijan model of Technology Leapfrogging. The Electronic Journal of Information Systems in Developing Countries. 84, e12027 (2018). https://doi.org/10.1002/isd2.12027.

14. Abdullahi, M., Abubakar, A., Aliyu, R., Umar, K., Umar, M., Sabiu, T., Naisa, F., Khalid, S., Abubakar, L.: The Nature of Small and Medium Scale Enterprises (SMEs): Government and Financial Institutions Support in Nigeria. International Journal of Academic Research in Business and Social Sciences. 5, 527 (2015).

15. Easterby-Smith, M., Lyles, M.A., Peteraf, M.A.: Dynamic capabilities: Current debates 
and future directions. British Journal of Management. 20, (2009).

16. Mohamud, M., Sarpong, D.: Dynamic capabilities: Towards an organizing framework. (2016). https://doi.org/10.1108/JSMA-11-2015-0088.

17. Islam, D.M.D.R., Mazumder, T.: Mobile application and its global impact. International Journal of Engineering \& Technology. 10, 72-78 (2010).

18. Bula, H.: Evolution and Theories of Entrepreneurship: A Critical Review on the Kenyan Perspective. International Journal of Business and Commerce. 1, 81-96 (2012).

19. Bălan, C.: The disruptive impact of future advanced ICTs on maritime transport: a systematic review. (2018). https://doi.org/10.1108/SCM-03-2018-0133.

20. Bezerra, J., Bock, W., Candelon, F., Chai, S., Choi, E., Corwin, J.., DiGrande, S., Gulshan, R., Michael, D.C., Varas, A.: The Mobile Revolution: How Mobile Technologies Drive a Trillion Dollar Impact, https://eliasgagas.files.wordpress.com/2015/03/the_mobile_revolution_jan_2015_tcm8 0-180510.pdf, last accessed 2017/07/18.

21. Twinomurinzi, H., Schofield, A., Hagen, L., Ditsoane-Molefe, S., Tshidzumba, N.A.: Towards a shared worldview on e-skills: A discourse between government, industry and academia on the ICT skills paradox. South African Computer Journal. 29, (2017). https://doi.org/10.18489/sacj.v29i3.408.

22. Voss, C., Perks, H., Sousa, R., Witell, L., Wünderlich, N.: Reflections on context in service research. Journal of Service Management. 27, (2016). https://doi.org/10.1108/JOSM-04-2015-0115.

23. Ayoung, A., Abbott, P., Kashefi, A.: The Influence of Intangible ('Soft') Constructs on the Outcome of Community ICT Initiatives in Ghana: A Gap Archetype Analysis. The Electronic Journal of Information Systems in Developing Countries. 77, 1-22 (2016). https://doi.org/10.1002/j.1681-4835.2016.tb00562.x.

24. Tennant, J.: Why 'context' is important for research, https://blog.scienceopen.com/2016/05/why-context-is-important-for-research/, last accessed 2019/10/23.

25. Takavarasha Jr, S., Hapanyengwi, G., Kabanda, G.: Using Livelihood Profiles for Assessing Context in ICT4D Resarch: A Case Study of Zimbabwe's Highveld Prime Communal. The Electronic Journal of Information Systems in Developing Countries. 79, 1-22 (2017). https://doi.org/10.1002/j.1681-4835.2017.tb00582.x.

26. Ongori, H.: Empowering Small and Medium Enterprises (SMEs) with Information Communication Technologies (ICTs): Global Perspective. EPRA International Journal of Economic and Business Review. 4, (2016).

27. Siqueira, E., Souza, C., Barbosa, A., Senen, D., Meirelles, F.: Using a digital divide index among enterprises in the context of public policies in Brazil. The Electronic Journal of Information Systems in Developing Countries. 85, e12088 (2019). https://doi.org/10.1002/isd2.12088.

28. Dasuki, S., Quaye, A., Abubakar, N.: An Evaluation of Information Systems Students Internship Programs in Nigeria: A Capability Perspective. The Electronic Journal of Information Systems in Developing Countries. 83, 1-19 (2017). https://doi.org/10.1002/j.1681-4835.2017.tb00614.x.

29. Sein, M., Henfridsson, O., Purao, S., Rossi, M., Lindgren, R.: Action Design Research. MIS Quarterly. 35, 37 (2011). https://doi.org/10.2307/23043488.

30. Mullarkey, M., Hevner, A.: An elaborated action design research process model. (2018). https://doi.org/10.1080/0960085X.2018.1451811.

31. McLaren, T., Buijs, P.: A Design Science Approach for Developing Information Systems Research Instruments, (2011).

32. Hevner, A., March, S., Park, J., Ram, S.: Design science in information systems research. MIS Quarterly: Management Information Systems. 28, 75-105 (2004).

33. Jeppesen, S.: Critical realism as an approach to unfolding empirical findings: thoughts 
on fieldwork in South Africa on SMEs and environment. The Journal of Transdisciplinary Environmental Studies. 4, 9 (2005).

34. Elder-Vass, D.: Re-examining Bhaskar's three ontological domains: The lessons from emergence. In: Lawson, C., Spiro Latsis, J., and Martins, N. (eds.) Contributions to Social Ontology. pp. 160-176. Routledge Taylor \& Francis Group (2013). https://doi.org/10.4324/9780203607473.

35. Mingers, J.: Realizing Information Systems: Critical Realism as an Underpinning Philosophy for Information Systems. Information and Organization. (2004).

36. Tolani, A., Owoseni, A., Twinomurinzi, H.: Exploring the effect of mobile apps on SMEs in Nigeria: a critical realist study. IFIP AICT. 551, 1-13 (2019). https://doi.org/https://doi.org/10.1007/978-3-030-18400-1_50.

37. Owoseni, A., Twinomurinzi, H.: The use of mobile apps to enhance SMEs in conditions of uncertainty: A case study from Lagos, Nigeria. In: Proceedings of the 10th Annual Pre-ICIS SIG GlobDev Workshop, Seoul, South Korea (2017).

38. George, D., Mallery, P.: SPSS for Windows step by step : a simple guide and reference 17.0 update. Allyn \& Bacon, Boston (2010).

39. Teece, D., Pisano, G., Shuen, A.: Dynamic Capabilities and Strategic Management. Strategic Management Journal. 18, 509-533 (1997).

40. Modell, S., Jacobs, K., Wiesel, F.: A process ( re ) turn ? Path dependencies , institutions and performance management in Swedish central government. 18, 453-475 (2007). https://doi.org/10.1016/j.mar.2006.12.001.

41. Soyer, A., Onar, S.Ç., Sanchez, R.: Overcoming path dependency and "lock-in" in competence building and competence leveraging processes. Research in CompetenceBased Management. 8, 25-44 (2017). https://doi.org/10.1108/S1744211720170000008002.

42. HBS: WeChat: A winner in China but a loser abroad, https://digital.hbs.edu/platformdigit/submission/wechat-a-winner-in-china-but-a-loser-abroad/, last accessed 2019/10/23.

43. Baierl, R., Grichnik, D., Herrmann, A.: Overcoming Path-Dependency with Entrepreneurial Self-Efficacy. (2013).

44. Djelic, M.-L., Quack, S.: Overcoming path dependency: Path generation in open systems. Theory and Society. 36, 161-186 (2007). https://doi.org/10.1007/s11186-0079026-0. 